\title{
Assessing the use of animal health platforms: User's needs, preferences and constraints
}

\author{
Juana Bianchini $^{1}$ | Xavier Simons ${ }^{2}$ | Christel Faes $^{3}$ | Gaëlle Nicolas ${ }^{4}$ | Aline Vilain ${ }^{2}$ | \\ Guy Hendrickx $^{4}$ | Claude Saegerman ${ }^{1}$
}

${ }^{1}$ Faculty of Veterinary Medicine, Research Unit in Epidemiology and Risk Analysis Applied to Veterinary Sciences (UREARULiege), Fundamental and Applied Research for Animals \& Health, FARAH) Centre, Liege University, Liege, Belgium

${ }^{2}$ Veterinary Epidemiology, Sciensano, Brussels, Belgium

${ }^{3}$ I-BioStat, Data Science Institute, Hasselt University, Hasselt, Belgium

${ }^{4}$ Avia-GIS, Zoersel, Belgium

\section{Correspondence}

Claude Saegerman, UREAR-ULiege, Fundamental and Applied Research for Animals \& Health (FARAH) Center, Faculty of Veterinary Medicine, University of Liege, Quartier Valley 2, Avenue de Cureghem 7 A, B42, B-4000 Liege, Belgium.

Email: claude.saegerman@uliege.be

Funding information

Federal Public Service of Health, Food Chain and Environment, Grant/Award Number: MORISKIN research project RT18/2

\begin{abstract}
Animal health information systems or risk analysis tools are indispensable not only for animal health surveillance, but also to observe the evolution and risk of disease incursion into a disease-free area. Given the various information that can be derived from these both animal information systems and risk analysis tools, different international and national organizations have customized or created their own systems/tools to provide specific information for use by the respective countries. Moreover, with the increase of technology and data storage, they have become more accessible and widely used by professionals in animal and human health sciences. This study aimed to establish user's preferences, needs and constraints in respect of these animal information systems and risk analysis tools. An online survey was conducted and answered by 213 respondents from 132 countries. The respondents were animal health or public health professionals in different employment sectors (mostly in government, research and university institutions) and various fields of competency (highest for animal and public health). The majority of respondents used the animal health information systems frequently and on a weekly basis, with prevention measures of diseases being regarded as the most useful information. Descriptive epidemiology was more used/needed than analytical epidemiology. Risk analysis was performed by the majority of the respondents (70\%), using a qualitative approach more than a quantitative or semi-qualitative. The primary objectives were to produce risk assessment and preparedness in areas involving origin and spread of animal diseases. The features most sought after in risk analysis tools were pathways of introduction and spread assessment. The level of satisfaction was higher for the platform which is most used by the respondents. Overall, these results could be taken into consideration when improving an already available platform, or when creating a new efficient tool.
\end{abstract}

\section{KEYWORDS}

animal and public health., animal health systems, likert scale, online cross-sectional survey, risk analysis 


\section{1 | INTRODUCTION}

Over the last two decades, increasing globalization has facilitated more extensive trade in animals and animal products. This increased movement of animals and animal products has resulted in an upsurge in the spread of novel and known infectious zoonotic and nonzoonotic, animal diseases (Bianchini et al., 2020) to new frontiers, as seen with the recent outbreaks in different European countries of African swine fever (Linden et al., 2019), Lumpy skin disease (Beard, 2016) and West Nile fever (Sambria et al., 2013). Therefore, now more than ever, animal health systems and risk analysis tools play crucial roles not only in managing and predicting threats by providing vital information on pernicious pathogens and associated risks.

Moreover, with the advances in data storage methods and computational power, animal health information systems and risk analysis tools have increased in their importance and have become essential tools for animal disease management and surveillance.

An animal information system is defined as any database tool, international, national or regional which provides information or data on animal or zoonotic diseases. Given the importance of information management, many national and international authorities have produced several animal information systems, which every day gain more importance in their use. Additionally, this may be used as a tool for risk analysis, surveillance and other animal disease vigilance activities (OIE, 2020). Notable examples of world animal health information systems are: i) the World Animal Health Information System (WAHIS) platform, from the World Organization for Animal Health OIE (OIE, 2019); and ii) the Global Animal Disease Information System (Empres-i) by the Food and Agriculture organization of the United Nations, FAO (FAO, 2014).

Efficient decision-making on risk management of animal disease threats requires knowledge of which disease poses the highest threat and should therefore receive more attention (Bianchini et al., 2020; Humblet et al., 2012). This ensures that policymakers and researchers allocate adequate resources for the prevention and surveillance of human and animal diseases. Risk analysis has consequently become an essential tool to facilitate disease prevention. Thus, different risk analysis tools have been created. These tools, with different functions or objectives, enable disease prioritization with respect to their incursion risk, each with different functions or objectives. Examples of such include i) MINTRISK, Method for INTegrated RISK assessment of vector-borne diseases, by Wageningen University \& Research (MINTRISK, 2015); ii) SVARRA (Vos et al., 2019), Rapid Risk Assessment tool for introduction of exotic disease to the Swedish animal population, and iii) SPARE (2020), Development of a Spatial risk assessment framework for Assessing exotic disease incuRsion through Europe (United Kingdom, Defra).

As such animal information systems and risk analysis tools have rapidly increased in use, by professionals with field activities, in animal health research and for disease control and prevention in both human and animals. Morris (1991) stated in 1991:
'As in most other technical and management fields, information management is fast becoming the key to effective action in animal health'. Thus, a modern veterinary authority or public service requires effective systems and tools for gathering relevant information from the field. In turn, this information should be processed such that it provides maximum value, and is presented in a form which easily informs national policymaking and effective disease control and prevention. Different professionals (in academia, livestock industry, policymaking) who use these systems and tools differ in the type and level of detail of the information they require. With respect of these animal information systems and risk analysis tools it is therefore important to establish first what are the professional expectations (preferences, needs and constraints) and second what are the related existing gaps. This online cross-sectional study aimed to obtain a general picture of what animal and public health professionals require of animal health systems and risk analysis tools and the constraints of these applications.

\section{2 | MATERIAL AND METHODS}

\section{1 | Study design and sampling}

An online cross-sectional study was set up to investigate the users' perceptions (e.g. needs, preferences and constraints) of animal health platforms and risk analysis tools. The study population consisted of professionals around the globe whose professional activities involved the use of different platforms; either animal health or risk analysis tools or both. For this, a survey was produced and distributed in two ways. Firstly, emails requesting participation in the proposed online questionnaire were sent by the authors to 573 professionals. Most of them were known professional contact points who were previously or at the time involved in animal or human health activities at different international levels. These same professionals were asked for them to send the questionnaire to other professionals who to their knowledge use animal health platforms and risk analysis tools (snowball sampling strategy) (Lupo et al., 2016). Secondly, in parallel, with the support of the World Organisation for Animal Health (OIE) the questionnaire was spread also to the OIE focal points.

\subsection{Data collection and survey}

The responses were collected in an anonymous online survey which was created, hosted and shared using the LimeSurvey ${ }^{\circledR}$ software. The survey questionnaire (Appendix S1) was divided into $6 \mathrm{sec}$ tions, each with a subset of questions: (i) personal information of the respondents, to have a general profile of people who use this type of tools (8 questions); (ii) utility of the animal health information systems, based on how often professionals used the systems and the type of information they sought (16 listed type of information 
and 17 questions in total); (iii) data sources, related to the issues and constraints regarding the data type that the respondents needed or had (19 questions); (iv) risk assessment tools - this part was only to be answered by professionals working in risk assessment. Questions were on type of risk assessment and what they are trying to achieve with it (21 questions); (v) perception of using animal health platforms or risk analysis tools (15 questions), and finally; (vi) the assessment of available animal health platforms or risk analysis tools (5 questions). In total, the questionnaire contained 85 questions, 66 of which required a response on a 5-point Likert scale (i.e. never, rarely, sometimes, very often, and always).

The questionnaire was sent in September 2019 and was open to responses until the 1st of November of the same year. It was anonymous, did not include personal or sensitive data, and according to the European legislation, did not specifically require approval by an Ethical Committee.

\section{3 | Data analysis}

Responses were extracted from the LimeSuervey ${ }^{\circledR}$ application to a Microsoft Excel ${ }^{\circledR}$ spreadsheet for analysis. Data were cleaned and records were deleted if the respondent did not complete the questionnaire.

Questions were grouped by thematic categories and described in terms of frequency and percentages. Likert scale responses were transformed into coded from 1 to 5 ( 1 being the lowest degree and 5 the highest). To estimate whether the Likert scale answer was significantly associated to the specified group, one of the following test was applied: i) Fisher's exact test when the expected number of answer was lower than 5 ; ii) $\chi^{2}$ otherwise. If significant ( $p$-value <.05), a univariate ordinal logistic regression was applied to determine the level of importance of the answers within the group. The explanatory variable was the group being analysed, inserted as a categorical variable and the outcome variable the coded Likert scale. The categorical variable was considered significant at $p$-value $<.05$.

To examine if there were differences between two or more groups the Kruskal-Wallis test was conducted with significance at $p$-value $<.05$.

Open-ended questions were sorted manually by theme or topic and summarized in an interpretative way. All statistical analyses were conducted using Microsoft Excel ${ }^{\circledR}$ and STATA S. E. $14.2^{\circledR}$ software (College Station, Texas, USA).

\section{3 | RESULTS}

\section{1 | Survey response}

A total of 573 emails with the link to the survey were sent to professionals around the world. A questionnaire was opened for 341 of these emails. After cleaning and deleting incomplete records, a total of 213 respondents completed the survey (i.e. $37 \%$ response rate 213/573).

\section{2 | Respondent's characteristics}

The most represented age group was $41-50$ years old with 82 respondents, followed by 51-60 (53 counts), 31-40 (51 counts), over 60 (14 counts) and the lowest group 20-30 (13 counts). The years of work experience ranged from 1 year to 40 with the majority of the respondents (38\%) having between 11 and 20 years' experience.

The number of respondents, who were carrying out their professional activities in a single country was 145 (13 of which did not specify which country) represented by 66 different countries. The countries with most representation were Belgium, France and Ireland with 18, 10 and 6 counts respectively (Figure 1).

A total of 68 professionals were working in several countries (i.e. at international level) of which 30 worked both in European and nonEuropean countries, 20 in European countries only and 18 in nonEuropean countries only.

Type of employment, field of competency and responsibilities related to animal health according to frequency of use of animal health systems are shown in Table 1. Respondents answered more than one type of employment and they were employed in government institutions (112/272), followed by research institutions (65/272), universities (52/272), international organizations $(16 / 272)$, private companies (9/272), as sector representatives $(5 / 272)$, animal producers (3/272), private veterinarians $(6 / 272)$, in consultancy companies (2/272), different non-governmental associations (3/272) and $1 / 272$ was a retired professional. The frequency of use was associated with type of employment (Fisher's exact test; $p$-value $<.05$ ).

For the univariate ordinal logistic regression the employment categories animal producer, sector representative and private company were grouped in a single category 'miscellaneous' due to low counts. Using university as the reference category, international organizations were those using the systems the most (Odds ratio $[O R]=9.59$; 95\% Confidence Interval $[95 \% \mathrm{Cl}]=2.79-9.71 ; p$-value <.001), followed by government institutions $(\mathrm{OR}=5.2 ; 95 \% \mathrm{Cl}=2.79-$ 9.71; $p$-value <.001), miscellaneous ( $\mathrm{OR}=4.36 ; 95 \% \mathrm{Cl}=1.91$ - 9.97; $p$-value $<.001)$ and research institutions $(\mathrm{OR}=1.72 ; 95 \% \mathrm{Cl}=0.89$ - 3.33; $p$-value $=0.11$ ) (Table 2a)

Multiple fields of competency were chosen, with animal health and public health (191/433 and 92/433 respondents, respectively) being the most common. This was followed by food safety (62/433), animal welfare (55/433), environment (15/433) and plant health (5/433). Other option included: animal husbandry (5/433), animal conservation and economics (3/433). Parasitology, epidemiology, global health, insect pest control, microbiology veterinary epidemiology and wildlife health, each had 1 count out 433.

The responsibilities they held regarding animal disease were mostly doing risk assessment (134/554) and signal capture 


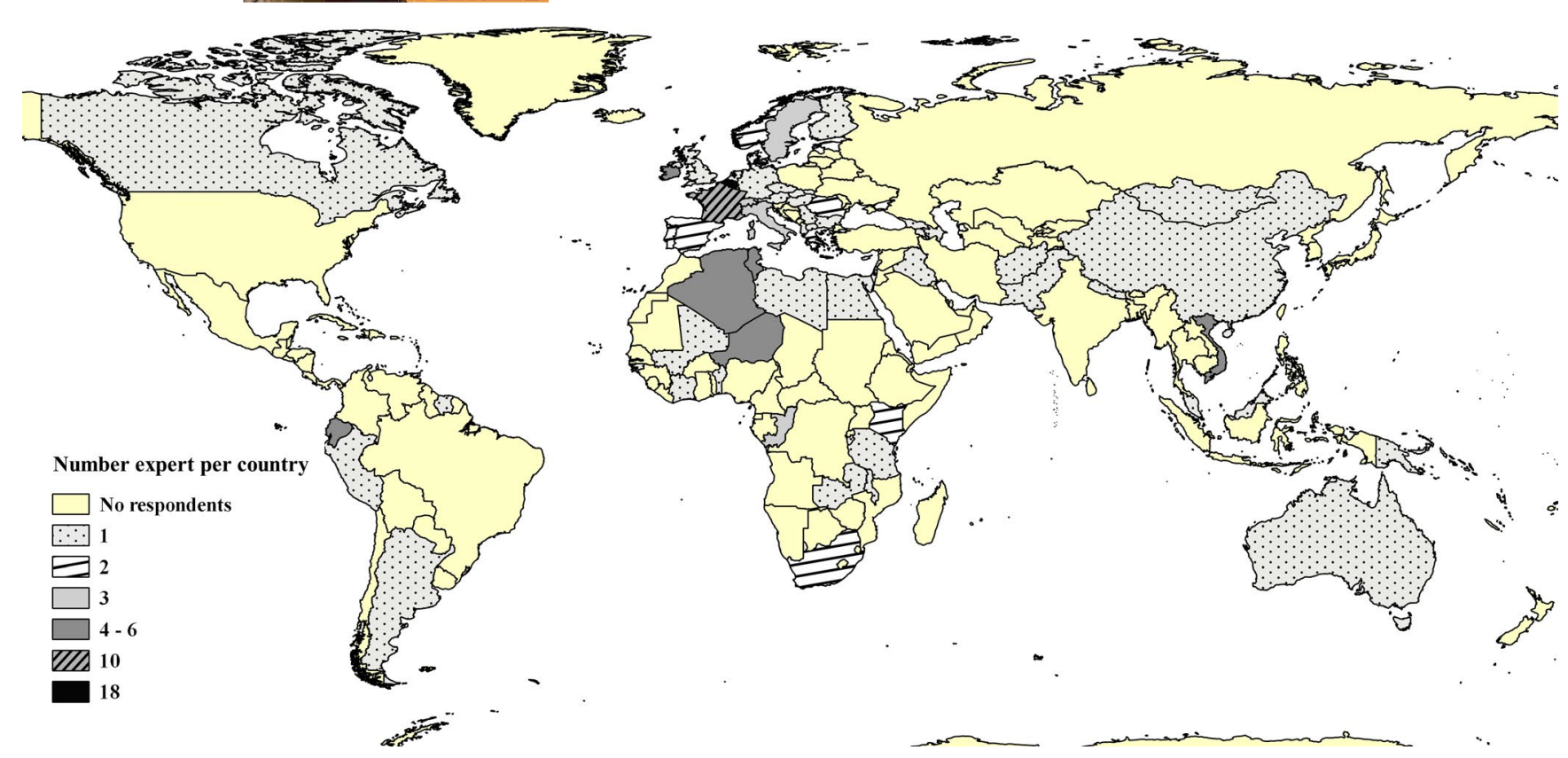

FIGURE 1 Map showing country of where the experts carry their professional activities $(N=132)^{*}{ }^{*} 132$ respondents answered specified the country

(102/554). Risk communication, risk management, policymaking and decision-making had similar counts with 85/554, 77/554, $66 / 554$ and 61/554 respectively. There were 32 counts for the option 'other' where on specification research and funding (9/32) and surveillance and control (8/32) had the highest counts. The frequency of use was not associated with field of competency nor the type of responsibilities the expert's held (Fisher's exact test; $p$-value $>.05$ ).

Experts mentioned that the key words which best described their areas of expertise were: epidemiology (59 times); animal health (43 times); zoonoses (20 times); surveillance (16 times); food safety (15 times); microbiology (12 times); animal husbandry (11 times); animal welfare (9 times); veterinary and veterinary epidemiology (8 times each); biosecurity (7 times); and contingency planning and virology (7 times each) (Figure 2).

\section{3 | Utility of animal health information systems}

When asked 'how frequently they use the animal health information systems', $1 \%$ of the respondents answered never, $9 \%$ rarely, $27 \%$ sometimes, $35 \%$ often and $29 \%$ always.

The answers of the experts showed that there was a significant difference among the different types of information available in the animal health systems (Appendix S1) and their degree of usefulness (Fisher's exact test $p<.05$ ). In general, most of the type of information was considered extremely useful and very useful (Figure 3). In the univariate ordinal logistic regression 'prevention measures' was the one regarded as most useful one with OR 4.67 times $(95 \% \mathrm{Cl}=3.27-6.67 ; p$-value $<.001)$ more likely to be useful compared to 'treatment' (Table 2 b). The type of information with the highest OR were 'efficiency of currently available control measures' (OR $=3.74 ; 95 \% \mathrm{Cl}=2.63-5.30 ; p$-value <.001), 'cases/incidence information' (OR $=3.70 ; 95 \% \mathrm{Cl}=2.61-5.24 ; p$-value $<.001)$, 'zoonotic potential' (OR $=3.68 ; 95 \% \mathrm{Cl}=2.58-5.25 ; p$-value $<.001)$, 'evolution/spread of the disease during time (days, weeks, months)' $(\mathrm{OR}=3.34 ; 95 \% \mathrm{Cl}=2.35-4.75, p$-value $<.001)$ and 'mapping display of cases' $(\mathrm{OR}=3.19 ; 95 \% \mathrm{Cl}=2.25-4.53$; $p$-value $<.001)$. The two with the lowest $\mathrm{OR}$, that is least important ones were 'produce risk estimations' $(\mathrm{OR}=1.7 ; 95 \% \mathrm{Cl}=1.20-2.41 ; p$-value <.001) and 'methodologies for risk analysis which have been described so far' (OR 1.5; 95\% Cl = $1.08-2.18 ; p$-value $=.016$ ).

\section{4 | Data sources}

Descriptive and analytical epidemiology type of data were equal in the category 'frequently' used and needed, with both having $44 \%$ of the answers (Figure 4). However, descriptive epidemiological data was more needed and used by the experts (Kruskal-Wallis test; $p$-value $=.02$ ). When comparing the data source's need versus their use, the Kruskal-Wallis test ( $p$-value $<.05$ ) showed that the need for data was greater than its use. This was consisted for each type of data source identified in the survey, scientific literature, international/national databases, national agencies, laboratories databases, expert opinion and questionnaires. (Figure 5). The three last aforementioned data sources where those where there was the most considerable difference between the need for data versus their use (i.e. experts had the most need for these data sources).

Table 3 show's that most of the respondents considered that they obtained/acquired data of fair (85/213) and good (105/213) quality, although many mentioned having sometimes (117/213) or 
TAB LE 1 Frequency of animal information systems use according to type of employment, field of competency and responsibility related to animal health

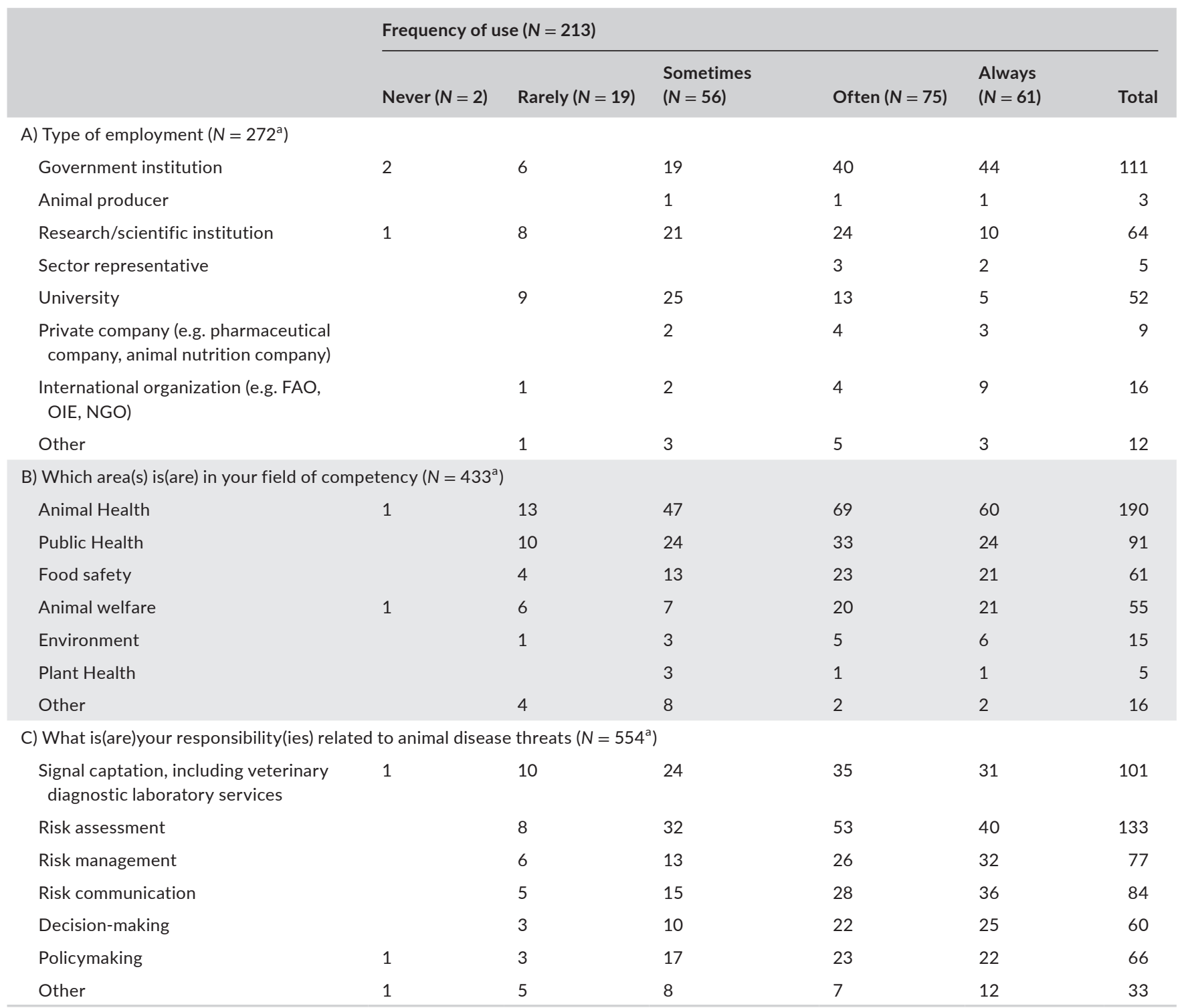

${ }^{a}$ The number of answers is higher than the number of respondents because more than one option could be chosen.

very often $(63 / 213)$ issues in obtaining data. There was no association between the difficulty in obtaining data and the data quality (Fisher's exact test; $p$-value $>.05$ ).

Data availability was suggested to be a bigger hurdle and constraint than data accessibility (Kruskal-Wallis; $p$-value <.05) (Figure 6). As to the preferred form of data, 38\% preferred Microsoft Excel, 27\% PDF, 17\% TEXT, 8\% HTLM and 10\% had no preference.

\section{5 | Risk analysis}

A total 150 respondents answered this section, thus $70 \%$ of the respondents produced risk assessments and used the available tools. There was a difference in the frequencies of type or risk analysis approach used by the experts (Figure 7a) being the qualitative approach used more than the quantitative or semi-qualitative (Fisher's exact test; $p$-value <.05). The univariate ordinal logistic regression model (Table $2 \mathrm{c}$ ) showed that the qualitative approach was used 3.73 times mores $(95 \% \mathrm{Cl}=2.42-5.75 ; p$-value $<.001)$ than the semiqualitative approach. Quantitative and semi-qualitative were used in equal frequency. The type of risk analysis assessments; release, exposure and consequence assessment were equally worked on (Figure 7b) (Kruskal-Wallis; $p$-value $=.12$ ).

The two primary objectives of the risk assessment where 'risk assessment and preparedness in areas involving origin and spread of animal diseases including zoonoses' and to 'provide stakeholders with relevant information and expert advice on issues related to disease preparedness and surveillance of animal diseases and zoonoses'. These obtained when combining both the 'very often' and 'always' categories $58 \%$ and $54 \%$ of the answers respectively (Figure 7c). The odd's obtained in the univariate ordinal logistic regression model for these two objectives where $\mathrm{OR}=2.53 ; 95 \% \mathrm{Cl}=1.68-3.82 ; p$-value 
TABLE 2 Results of all the univariate ordinal logistic regression models (OLS)

\begin{tabular}{|c|c|c|c|}
\hline Model & $\begin{array}{l}\text { Odds } \\
\text { Ratio }\end{array}$ & $\begin{array}{l}95 \% \\
\text { Confidence } \\
\text { interval }\end{array}$ & $\begin{array}{l}p- \\
\text { value }\end{array}$ \\
\hline \multicolumn{4}{|c|}{ OLS 2a) Frequency of use with type of employment } \\
\hline \multicolumn{4}{|l|}{ Type of employment } \\
\hline University (Ref)* & --- & --- & --- \\
\hline $\begin{array}{l}\text { Miscellaneous: Animal producer, } \\
\text { sector representative, private } \\
\text { company }\end{array}$ & 4.36 & $1.91-9.97$ & $<.001$ \\
\hline Government institution & 5.20 & $2.79-9.71$ & $<.001$ \\
\hline International organization & 9.59 & $3.16-29.13$ & $<.001$ \\
\hline Research/scientific institution & 1.72 & $0.89-3.33$ & .105 \\
\hline \multicolumn{4}{|c|}{$\begin{array}{l}\text { OLS } 2 b \text { ) Information found useful when using animal information } \\
\text { systems }\end{array}$} \\
\hline \multicolumn{4}{|c|}{ Type of information } \\
\hline Treatment (Ref)* & --- & --- & --- \\
\hline Prevention measures & 4.67 & $3.27-6.67$ & $<.001$ \\
\hline $\begin{array}{l}\text { Efficiency of currently available } \\
\text { control measures }\end{array}$ & 3.74 & $2.63-5.30$ & $<.001$ \\
\hline Cases/incidence information & 3.70 & $2.61-5.24$ & $<.001$ \\
\hline Zoonotic potential & 3.68 & $2.58-5.25$ & $<.001$ \\
\hline $\begin{array}{l}\text { Evolution/spread of the disease } \\
\text { during time (days, weeks, months) }\end{array}$ & 3.34 & $2.35-4.75$ & $<.001$ \\
\hline Mapping display of cases & 3.19 & $2.25-4.53$ & $<.001$ \\
\hline Vector information & 2.86 & $2.02-4.07$ & $<.001$ \\
\hline Aetiologic agent & 2.35 & $1.65-3.34$ & $<.001$ \\
\hline Diagnostic methods & 2.59 & $1.81-3.68$ & $<.001$ \\
\hline Host & 2.25 & $1.59-3.19$ & $<.001$ \\
\hline Disease information (e.g. Factsheet) & 2.52 & $1.78-3.57$ & $<.001$ \\
\hline $\begin{array}{l}\text { Regulations which are in place } \\
\text { currently regarding a specific disease }\end{array}$ & 2.01 & $1.42-2.84$ & $<.001$ \\
\hline $\begin{array}{l}\text { Methodologies for risk analysis } \\
\text { which have been described so far }\end{array}$ & 1.54 & $1.08-2.18$ & .016 \\
\hline Produce risk estimation & 1.70 & $1.20-2.41$ & .003 \\
\hline Pathogenesis of the disease & 1.26 & $0.89-1.80$ & $.191^{* *}$ \\
\hline
\end{tabular}

OLS 2c)Risk analysis assessment approach used by the experts

Risk assessment approach

Semi-qualitative (Ref)*

Qualitative

$---$

Quantitative

$3.73 \quad 2.42-5.75<.001$

$1.13 \quad 0.74-1.72 \quad .574^{* *}$

OLS 2d) Primary objectives of the experts when doing risk assessment

Objectives

Identify plausible future scenarios to be prepared to future animal incursions (Ref)*

Risk assessment and preparedness in areas involving origin and spread of animal diseases, including zoonoses
TABLE 2 (Continued)

\begin{tabular}{|c|c|c|c|}
\hline Model & $\begin{array}{l}\text { Odds } \\
\text { Ratio }\end{array}$ & $\begin{array}{l}95 \% \\
\text { Confidence } \\
\text { interval }\end{array}$ & $\begin{array}{l}p \text { - } \\
\text { value }\end{array}$ \\
\hline $\begin{array}{l}\text { Provide stakeholders with relevant } \\
\text { information and expert advice } \\
\text { on issues related to disease } \\
\text { preparedness and surveillance of } \\
\text { animal diseases and zoonoses }\end{array}$ & 2.27 & $1.51-3.4$ & $<.001$ \\
\hline $\begin{array}{l}\text { Identify key questions for targeted } \\
\text { research }\end{array}$ & 1.2 & $0.8-1.81$ & $.37^{* *}$ \\
\hline $\begin{array}{l}\text { Provide veterinary diagnostic } \\
\text { laboratory services for zoonotic, } \\
\text { epizootic and other animal } \\
\text { notifiable diseases }\end{array}$ & 0.76 & $0.5-1.17$ & $.213^{* *}$ \\
\hline $\begin{array}{l}\text { Evaluate the need for action to } \\
\text { support policy changes }\end{array}$ & 1.42 & $0.95-2.14$ & $.09^{* *}$ \\
\hline
\end{tabular}

OLS 2e) Features which are important to obtain when experts use a risk analysis platform/tool

Type of feature

Produce a risk assessment for two diseases for comparison

Spread assessment (Ref)*

Pathways of introduction of a disease until the border

Produce a quick risk assessment

Be able to produce a report using the information system

Produce a risk assessment only $\quad 3.03 \quad 1.99-4.62<.001$ detailed for a single disease

OLS 2f) Most important features looked for in previously used animal information systems

Feature

To be able to customize the interface and functionality you use (Ref)*

Data accessibility and availability

Extraction of information

$8.02 \quad 5.19-12.39<.001$

$5.86 \quad 3.80-9.05<.001$

$5.51 \quad 3.56-8.52<.001$

$3.96 \quad 2.56-6.14<.001$

Extraction of result/information

User Friendly

Display of information

The way results are displayed

Easy to find during web search

Risk assessment methodologies

Access software and information while off campus work

Easy contact for help

Publications

$12.32 \quad 8.47-17.93<.001$

$7.88 \quad 5.44-11.44<.001$

$7.06 \quad 4.88-10.21<.001$

$5.5 \quad 3.83-7.89<.001$

$5.28 \quad 3.67-7.59<.001$

$3.68 \quad 2.56-5.28<.001$

$3.24 \quad 2.25-4.66<.001$

$2.95 \quad 2.05-4.26<.001$

$2.421 .68-3.49<.001$

Login fewer times

$2.11 \quad 1.45-3.05<.001$

$2.05 \quad 1.43-2.95<.001$

$1.01 \quad 0.7-1.47 \quad .955^{* *}$

*Ref, Reference category.

${ }^{* *}$ Not significant.

$<.001$ and $\mathrm{OR}=2.27 ; 95 \% \mathrm{Cl}=1.51-3.4 ; p$-value $<.001$, respectively when compared to the reference category 'identify plausible future scenarios to be prepared to future animal incursions' (Table $2 \mathrm{~d}$ ). 


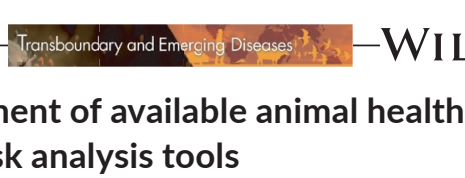 \\ 3.7 Assessment of available
platforms or risk analysis tools}

There was a significant importance to what experts want to obtain when using a risk analysis tool (Fisher's exact test; $p$-value $<.05)$. The feature 'spread assessment' had the highest percentage in the extremely and very important categories (72\% the total of both). On the other end, the objective 'produce a risk assessment for two diseases for comparison' having the lowest percentage $24 \%$ for the total of both categories (Figure 8 ). Thus, the univariate ordinal logistic regression (Table 2e) showed that 'spread assessment' had an OR $=8.02 ; 95 \% \mathrm{Cl}=5.19-12.39 ; p$ value <.001 compared to the reference category, 'produce a risk assessment for two diseases for comparison'. This was followed by 'pathways of introductions of a disease until the border' and 'produce a quick risk assessment' (OR $=5.86 ; 95 \% \mathrm{Cl}=3.8-9.05$; $p$-value $<.001$ and $\mathrm{OR}=5.51 ; 95 \% \mathrm{Cl}=3.56-8.52 ; p$-value $<.001$ respectively).

To assess the risk of threat, 128/150 of the respondents used different data sources and tools. However, only 49/150 answered that they combined the outputs of several types of methods to report the risk assessment.

\section{6 | Perception on using animal health platforms or risk analysis tools}

When evaluating the systems or tools the respondents usually worked with, there was a total of 198 respondents to this section. The user opinion was equally shared ( $51 \%$ saying yes and the remainder saying no) regarding the question of systems or tools being user friendly.

As to the issues or problems they encountered ( $N=397$ responses) these were in decreasing order: data accessibility (34\%), not enough information (32\%), slow (17\%), difficult to understand the page (12\%) and other (6\%). When observing the two subgroups of user friendly or not (Figure 9), respondents who did not find the animal information systems user friendly considered the biggest issue to be difficulties understanding the page (69\%). On the other spectrum, the respondents who did find these systems user friendly had an issue with the systems being slow (48\%).

For the features found in animal health systems, 'data accessibility' and 'extraction of information' were considered those of extreme importance, expert's giving it a $49 \%$ and $41 \%$ respectively in these two categories (Figure 10). The least important was to be able to customize the interface and functionality with only $10 \%$ of the expert's considering extremely important. There was as an association between the level of importance and the type of feature (Fisher's exact test; $p$-value <.05) and the univariate ordinal logistic regression (Table $2 \mathrm{f}$ ) showed an $\mathrm{OR}=12.32 ; 95 \% \mathrm{Cl}=8.47-17.93$; $p$-value $<.001$ in the category 'data accessibility and availability' This was followed by 'extraction of information', 'extraction of results/information' with OR of $7.88 ; 95 \% \mathrm{Cl}=5.44-11.44 ; p$-value $<.001$ ) and $\mathrm{OR}=7.06 ; 95 \% \mathrm{Cl}=4.88-10.21 ; p$-value <.001), The rest of the listed features (Table $2 \mathrm{f}$ ) were in the OR's range of 2.15.5 ( $p$-values <.001).
A total of 147 respondents assessed animal health platforms or risk analysis tools. The three animal health information systems they mostly used the WAHIS/WAHID (i.e. the platform of the OIE) was the one mentioned the most with 117/369, followed by the FAO database (Empres-i) 38/369, the database of the International society for infectious disease - (ProMED) 37/369 and the European animal notification system (ADNS) with 17/369. Sixty-two used this platform every day while 7 responded once a semester (Table 4). The percentage of satisfaction was not similar among the 3 groups having median of $75 \%, 70 \%$ and $63.5 \%$ for most used, intermediate use and least used respectively (KruskalWallis; $p$-value <.001) (Figure 11).

\section{4 | DISCUSSION}

This study is a first attempt at reporting the uses of and perspectives on animal information systems and risk analysis tools by professionals from all around the world. To date, attitudes towards the use of these platforms (either animal health systems or risk analysis tools) have not been analysed. There are similar surveys that have been conducted but referring specifically to a single animal health information system (i.e. analysing the WAHIS database only or giving general summary of animal health platforms) (FAO, 2011; OIE, 2017, 2020). This same point highlights a limitation of this study. It only provides a general picture of the constraints and attitudes, although there are a wide range of animal health information systems in operation at various levels (FAO, 2011; OIE, 2020) as well as risk analysis tools (Bellet et al., 2012). Thus, to be able to provide detailed information a larger study, specific to these systems or tools would be required.

The response rate to this study could be considered as overestimated given the fact that a snowball strategy was used. The anonymous form of the survey forbids quantification of the number of experts who could have been added to the survey using the network of the original set of identified professional (snowball strategy) (Lupo et al., 2016). Although a low response rate was achieved, this strategy provided a good representation of professionals who used the systems as the survey was specifically sent to focal points responsible for notifying animal diseases. It is important to highlight that the sample would have differed if the snowball strategy for example was used in an institution of a university in a specific country. In such case, the sample would have more accurately represented the preference of the specific country's universities and other issues or restraints. With this in consideration there was a good representation of years of experience in the field and age of the respondents were well represented. Additionally, the sample population carried out their professional activities from a broad range of nations, which gives a good general picture of the uses of these systems at an international level. Most respondents were employed in governmental 


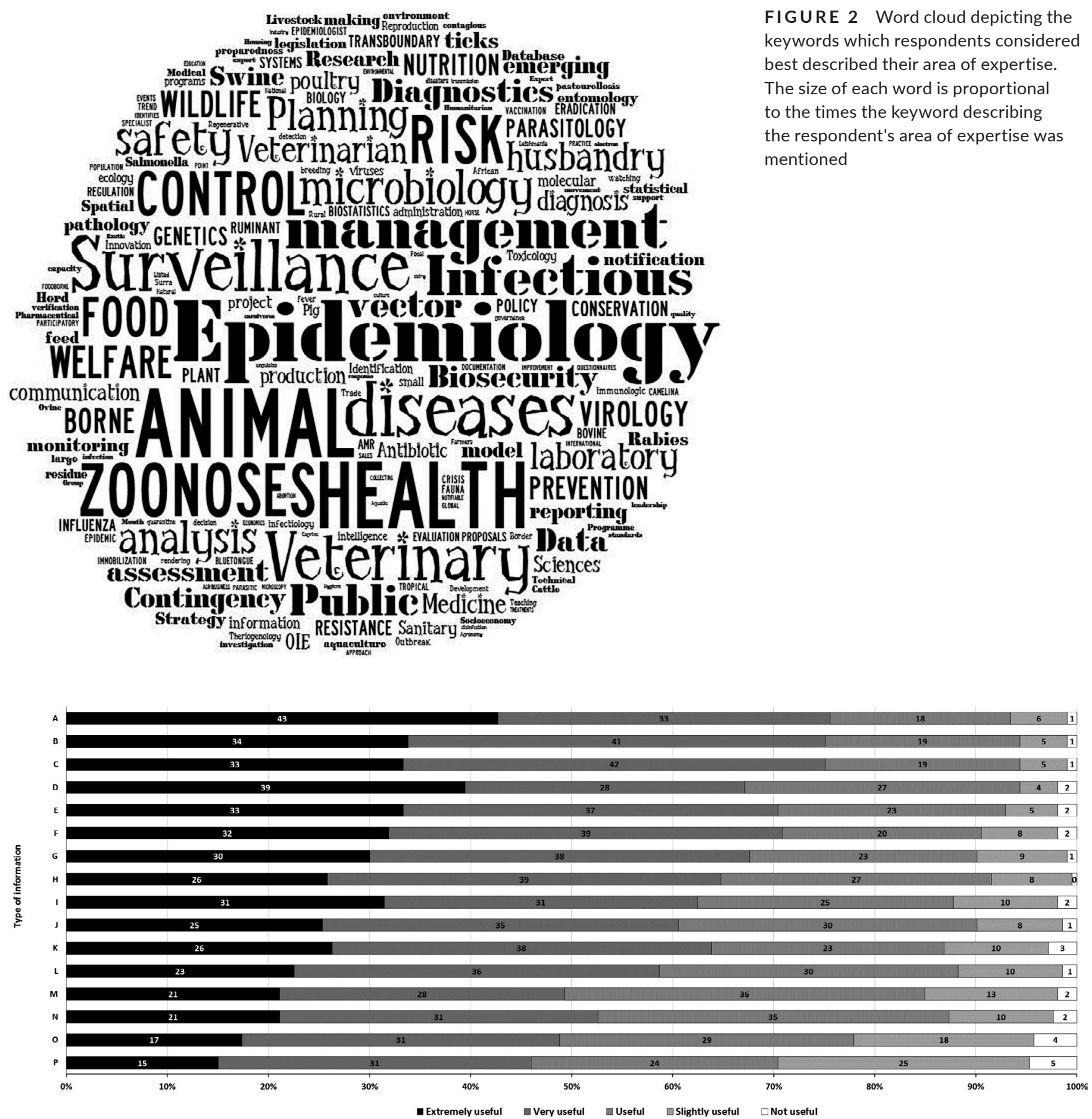

FIGURE 3 Degree of usefulness according to the respondents of type of information found in animal health systems. In decreasing order by extremely useful ( $N=213$ ). (A) Prevention measures; (B) Efficiency of currently available control measures; (C) Cases/incidence information; (D) Zoonotic potential; (E) Evolution/spread of the disease during time (days, weeks, months); ( F) Mapping display of cases; (G) Vector information; (H) Aetiologic agent; (I) Diagnostic methods; (J) Host; (K) Disease information (e.g. Factsheet); (L) Regulations which are in place currently regarding a specific disease; (M) Methodologies for risk analysis which have been described so far; (N) Produce risk estimation; (O) Pathogenesis of the disease; and (P) Treatment

institutions; however, those who use most animal health information systems were those working for international organization. This could be due to the fact that most animal information systems used by the respondents were those produced by the OIE and FAO and the snowball strategy used OIE focal points. Furthermore, professionals in international organizations are more likely to have easier access and a higher level of understanding of using the different animal health systems and/or risk analysis tools.

Respondents of this survey frequently use the animal information systems, mostly descriptive epidemiology data. The types of information they find most useful, are those related to the prevention and control of disease incursions and epidemiological characteristic of 
FIGURE 4 Type of data used or needed by the respondents ( $N=213$ ). Descriptive epidemiology: data on morbidity, mortality, spatio-temporal distribution, demography of hosts. Analytical epidemiology: factors of disease introduction, surveillance network, risk analysis

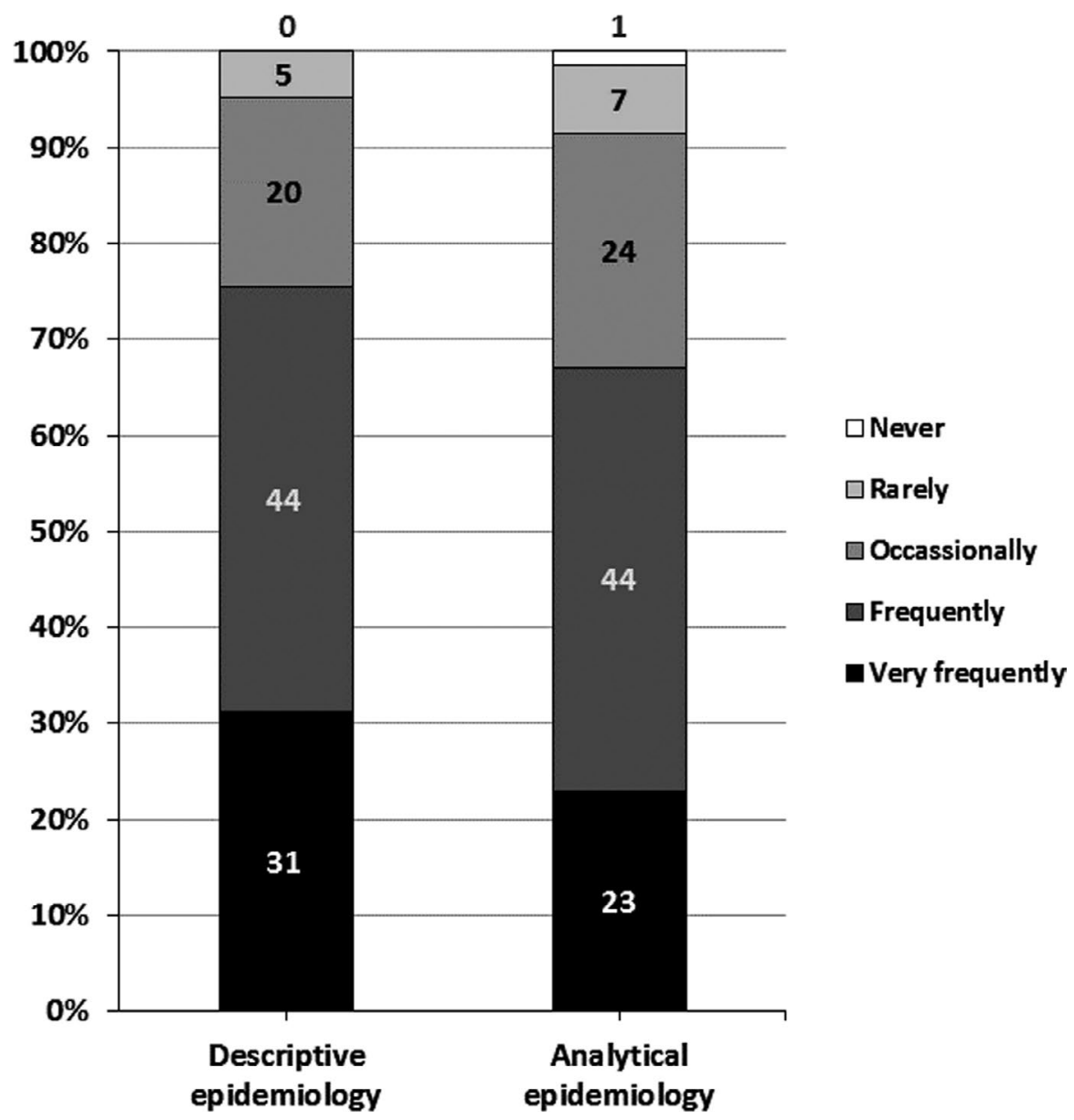

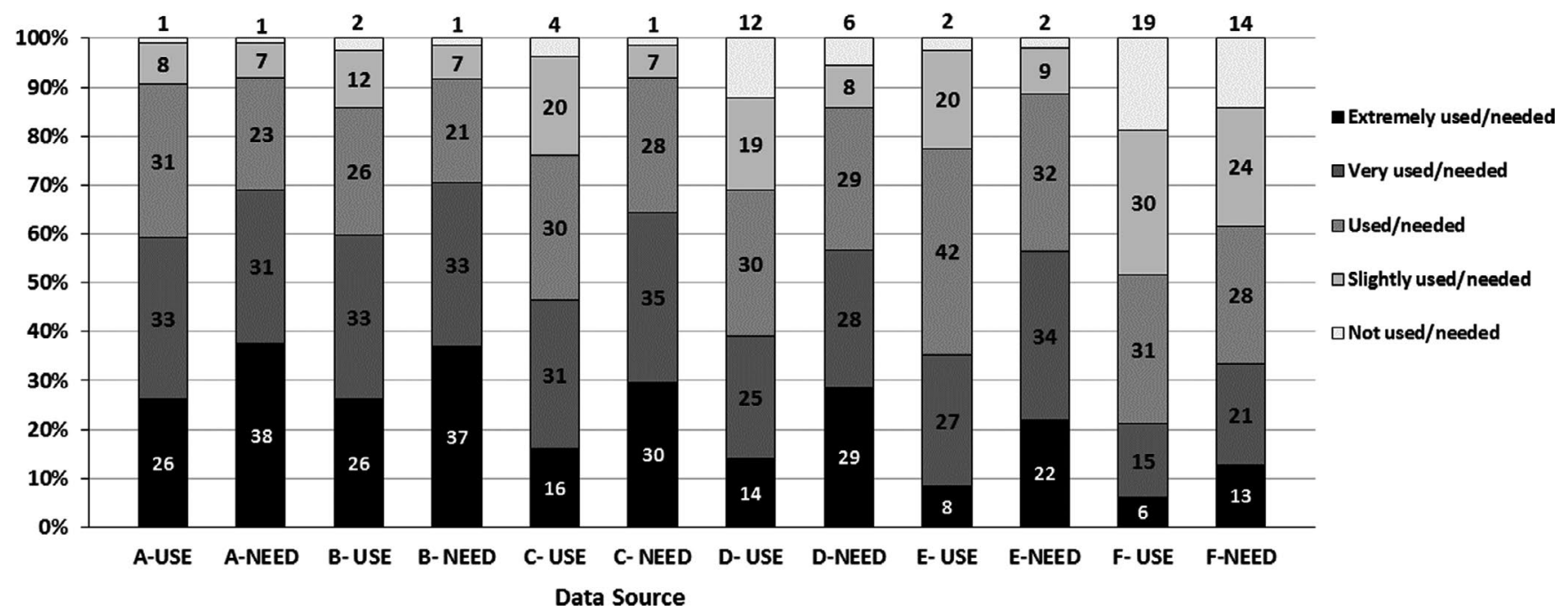

FIGURE 5 Type of data sources needed and used for the respondents daily work $(N=213)$. Data source (A) Scientific literature (i.e. published papers in peer reviewed journals, (B) International/national databases, such as those from the OIE, WHO. EUROSTAST, FAOSTATS, EFSA, ECDC, (C) National agencies (data comes from the member states' national institution, (D) laboratories databases, (E) expert opinion, (F) Questionnaires

diseases. This primarily concerns information related to surveillance of animal diseases and zoonoses. As such, they always have a need for different sources of data in particular laboratory databases, expert opinion and questionnaires. The experts' need for laboratory databases is to be given particular emphasis; as a comprehensive analysis of laboratory dataset is potentially pivotal in contributing to the epidemiological analysis of a disease (FAO, 2011). Thus, laboratory databases should be more readily available in animal information systems.

Data in animal health systems are crucial for epidemiological analysis and even if it is evident that there have been advances 


\begin{tabular}{|c|c|c|c|c|c|c|}
\hline \multirow[b]{2}{*}{ Data quality } & \multicolumn{6}{|c|}{ Is data obtaining/acquiring data an issue } \\
\hline & $\begin{array}{l}\text { Never } \\
(N=2)\end{array}$ & $\begin{array}{l}\text { Rarely } \\
(N=16)\end{array}$ & $\begin{array}{l}\text { Sometimes } \\
(N=117)\end{array}$ & $\begin{array}{l}\text { Very often } \\
(N=63)\end{array}$ & $\begin{array}{l}\text { Always } \\
(N=15)\end{array}$ & $\begin{array}{l}\text { Total } \\
(N=213)\end{array}$ \\
\hline Very poor & 1 & 1 & 0 & 0 & 1 & 3 \\
\hline Poor & 0 & 1 & 6 & 3 & 4 & 14 \\
\hline Fair & 0 & 5 & 52 & 28 & 0 & 85 \\
\hline Good & 1 & 8 & 56 & 31 & 9 & 105 \\
\hline Excellent & 0 & 1 & 3 & 1 & 1 & 6 \\
\hline
\end{tabular}

TABLE 3 Opinion on the quality/ reliability of data the respondents $(N=213$ ) obtain and if they have issues obtaining or acquiring data

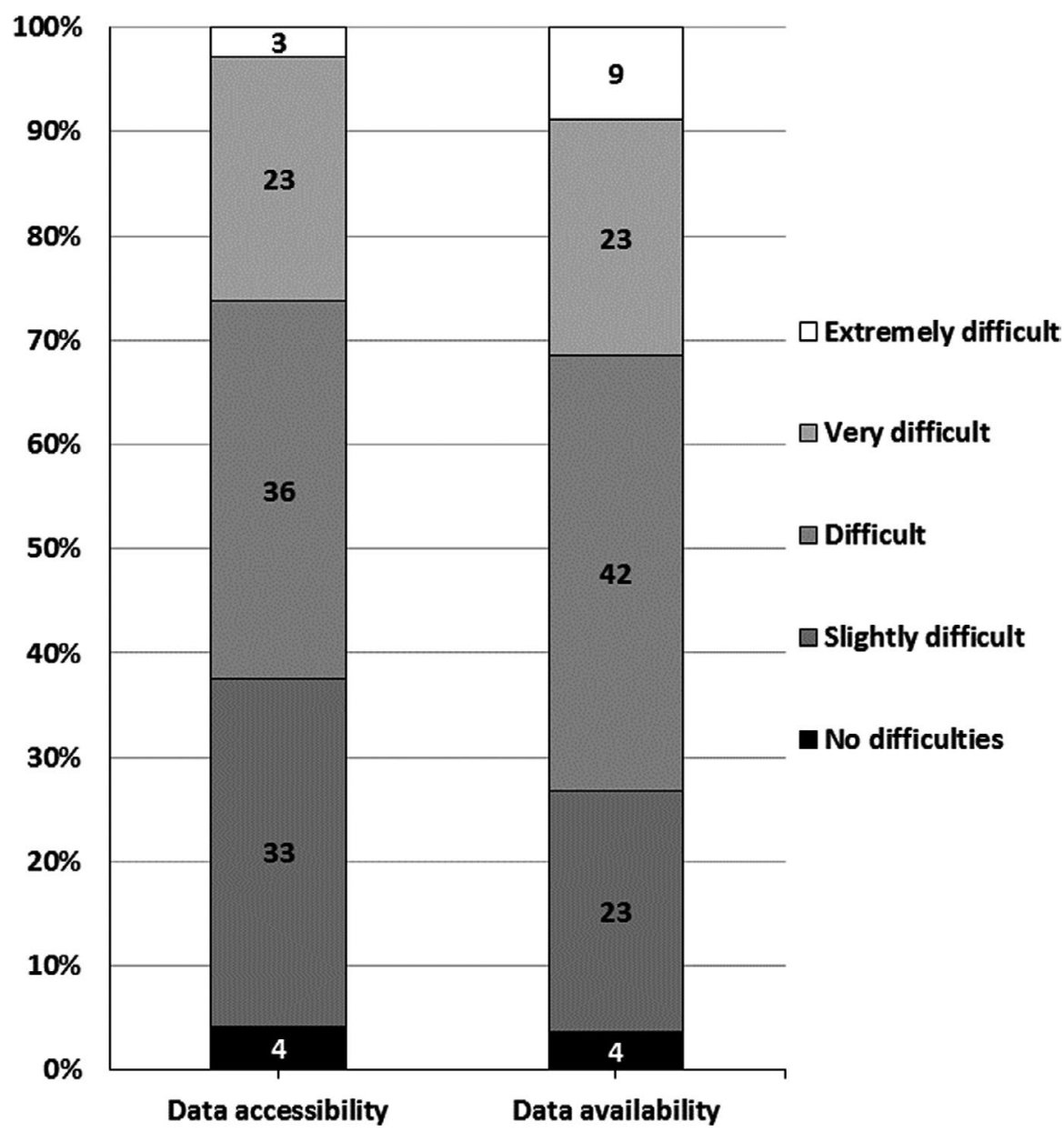

FIGURE 6 Hurdle(s) and constraints in obtaining data on animal health $(N=213)$. Data accessibility: Physical conditions in which users can obtain data (e.g. where to go, how to order, delivery time). Data availability: degree to which data can instantly accessed

in collecting data and improvement in animal health systems (FAO, 2011; OIE, 2017), there is yet a strong need for improving data availability and accessibility; not only for decision makers but also for research scientists (Humblet et al. 2016). This is reflected in the results of this survey which showed that for the respondents, the overall main issue and constraint they indicated was in fact data accessibility and availability. Consequently, it was also the main key feature that respondents looked for in an animal information system with this feature 12 times more important than the other listed features. Therefore, although there is accessibility to certain data (e.g. by officially demanding access to international organizations) limitations in access is still high as stated in previous studies (Bellet et al., 2012; Humblet et al., 2016). Moreover, current existing databases for animal health data have not always been designed with the potential for exchange of data and accessibility to a variety of stakeholders (Humblet et al., 2016).

Another constraint was the fact that the preferred forms of data of the respondents of this survey where in Microsoft Excel and PDF, but the main forms of data found by Humblet et al. (2016) were as PDF and HTLM files. Thus, professional are forced to try to adapt the forms of data to they require. Moreover, raw tabulated data (e.g. EXCEL and TEXT files) which are more appropriate for risk assessment are not often available and sometimes difficult to access (e.g. restricted or paying access) (Bellet et al., 2012). Additionally, heavy manual work may be required from the user to convert the data in the desired form (Humblet et al. 2016), which may lead to errors. Given that, both animal health systems and risk analysis tools are an important source of data these should have the required appropriate 
(a)

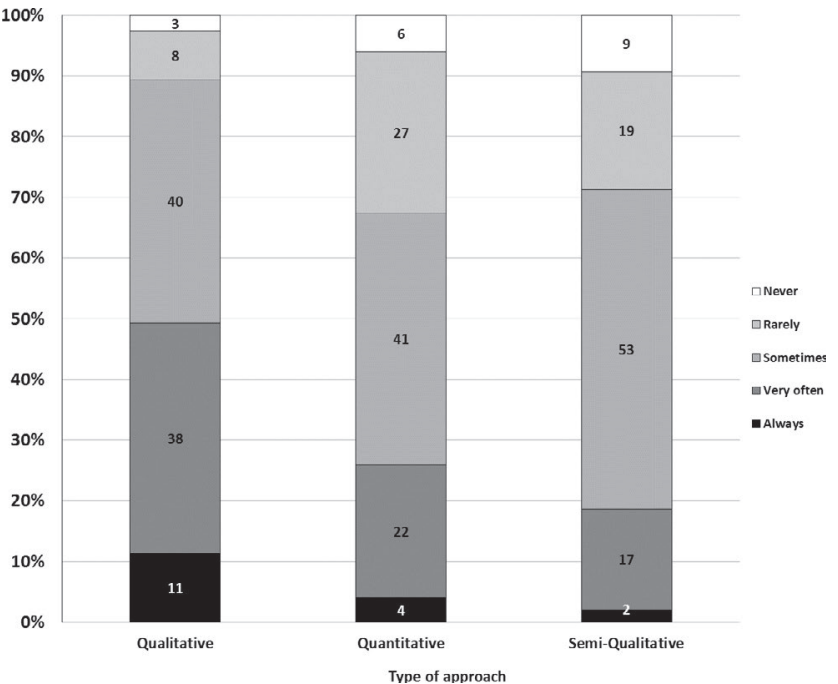

(c)

A

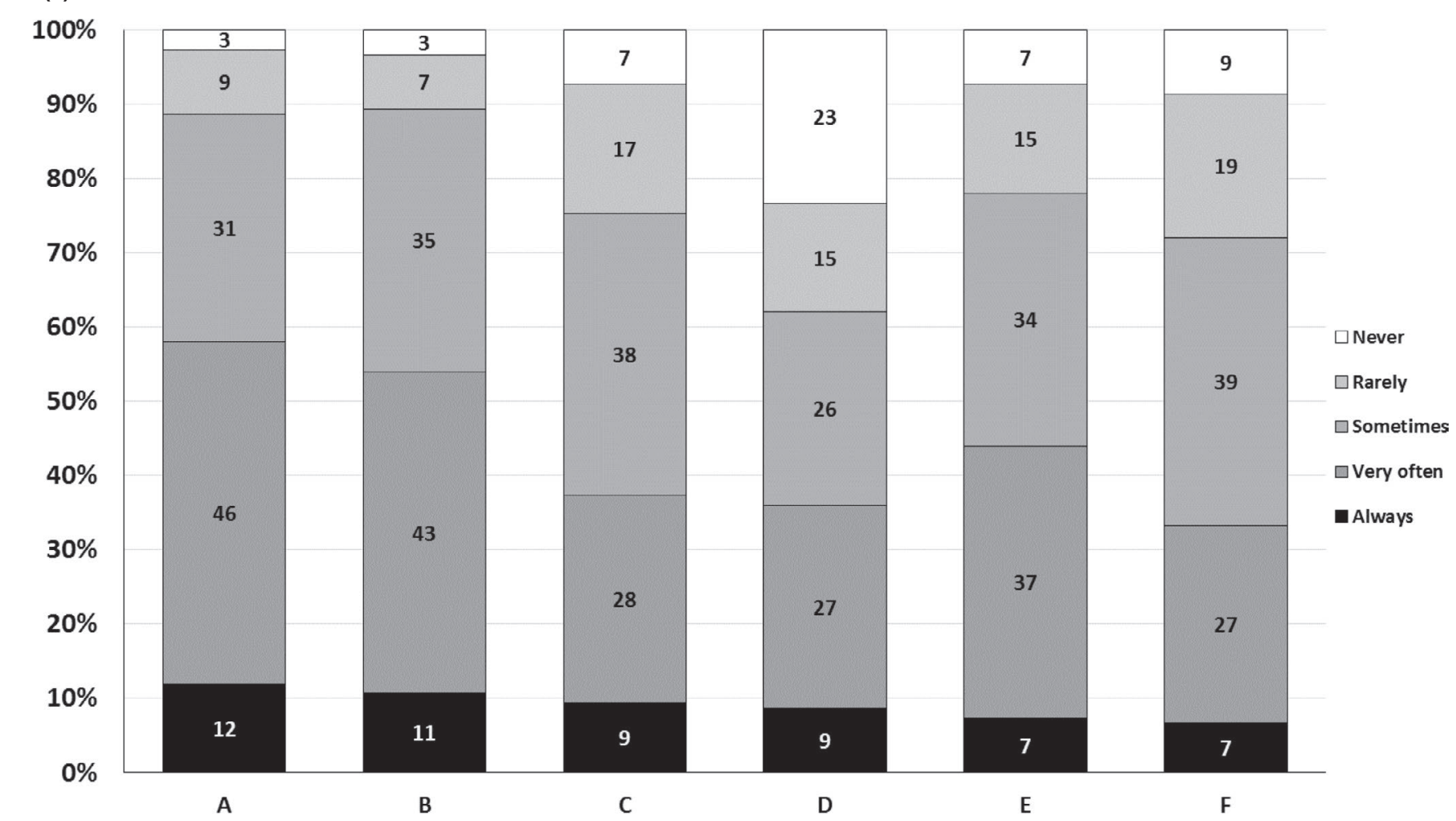

(b)

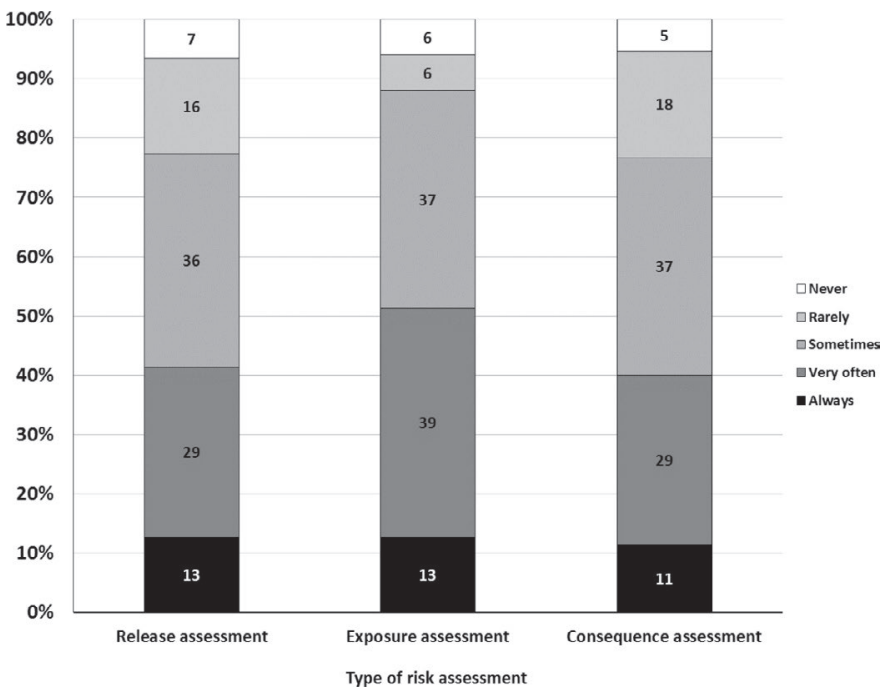

Primary objective

FIGURE 7 Types of approach, what they work on and primary objective of the risk assessments done by the respondents. (a) Type of risk assessment approach used ( $N=150)$. Legend: Qualitative: An assessment where the output on the likelihood of the outcome or the magnitude of the consequences are expressed in qualitative terms such as high, medium, low or negligible. Quantitative: An assessment where the outputs of the risk assessment are expressed numerically. (b) Type of risk assessment they work on ( $N=150)$. Legend: Release assessment: estimation of the likelihood of a hazard being introduced in a particular zone. Exposure assessment: estimation of the likelihood of susceptible humans or animals being exposed to the hazard. Consequence assessment: Describing the results of the release and exposure to the hazard for humans and animals (health and/or economic consequences). (c) Primary objectives of the risk assessment ( $\mathrm{N}=150)$. Legend : (A) Risk assessment and preparedness in areas involving origin and spread of animal diseases, including zoonoses (B) Provide stakeholders with relevant information and expert advice on issues related to disease preparedness and surveillance of animal diseases and zoonoses (C) Identify key questions for targeted research (D) Provide veterinary diagnostic laboratory services for zoonotic, epizootic and other animal notifiable diseases (E) Evaluate the need for action to support policy changes (F) Identify plausible future scenarios to be prepared to future animal incursions 


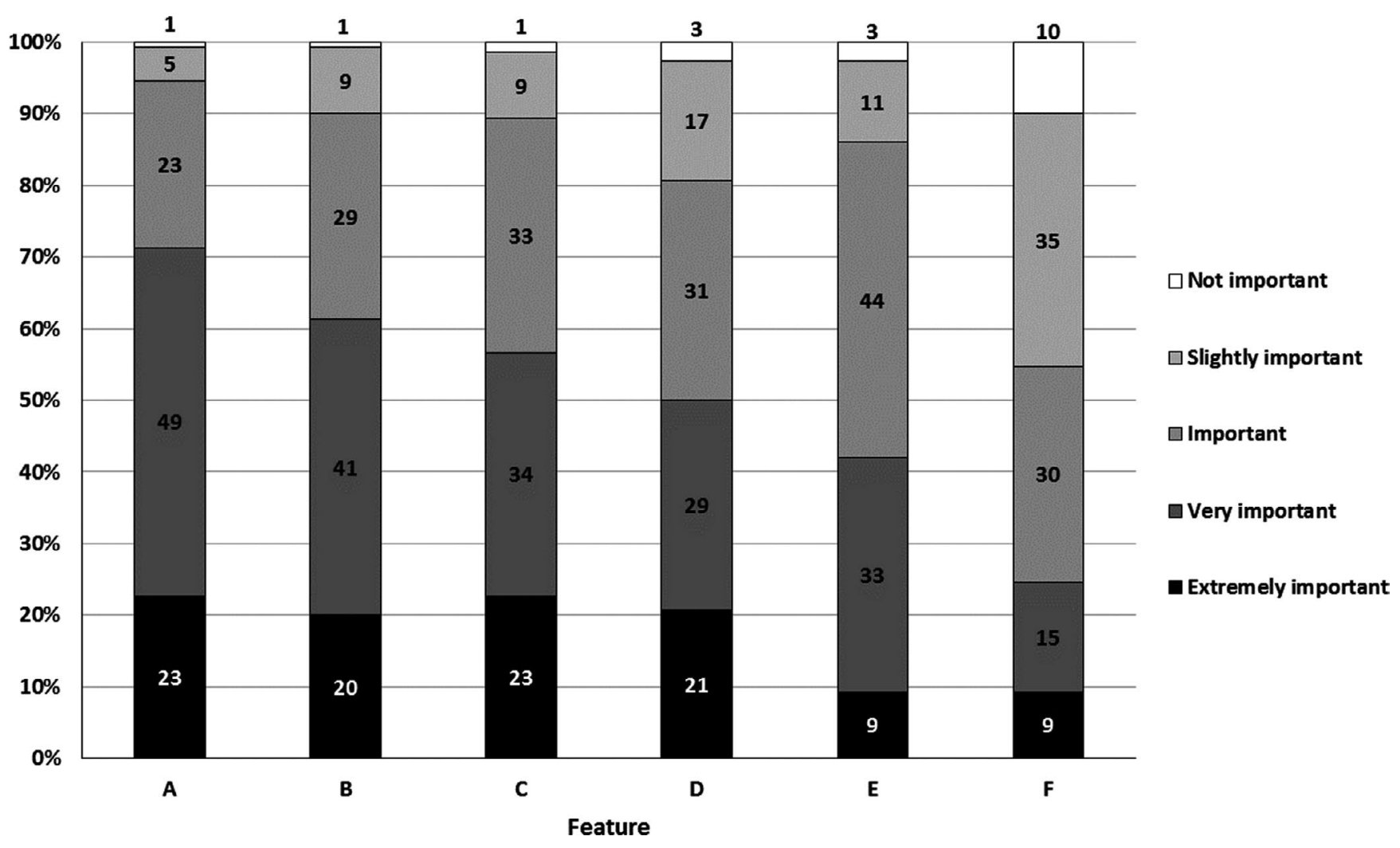

FIGURE 8 Features which are important for the respondents $(N=150)$ to obtain when using a risk analysis platform/tool. Legend. (A) Spread assessment; (B) Pathways of introduction of a disease until the border; (C) produce a quick risk assessment; (D) Produce a report using the system; (E) Produce a risk assessment detailed for a single disease; (F) Produce a risk assessment for two diseases for comparison

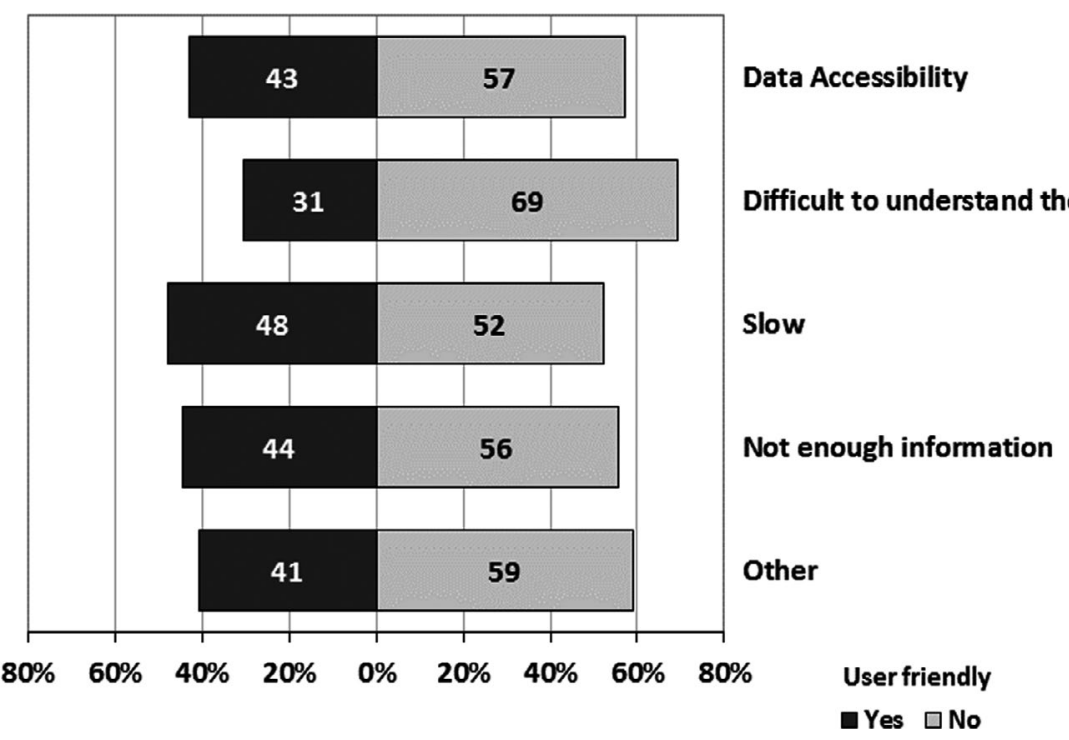

FIGURE 9 Main issues encountered when using animal health platforms or risk analysis tools by if they find these user friendly or not ( $\mathrm{N}$ responses $=397$ )

$\square$ Yes $\square$ No

forms. As such, data formatting is important criteria when developing animal health systems.

It is important to consider there could be among respondents, a lack of knowledge on known databases and mechanisms of extraction, limitation in technology in manipulating data or there could be limitations given by the countries conditions (50\% of the respondents found limiting because of their countries' condition) with respect to access to technology, specific information on animal health or software for data analysis. No assumption on the reasons of such a limitation per country could be made from this survey as the responses in this survey were analysed as a group (i.e. without dividing it into subgroups by professionals' provenance) and did not compare relationship between issues or restraints and regions (i.e. differences in terms of animal health institutionalization or data accessibility). It would benefit future research to compare the functionality of different national health systems. Experts could be asked what the constraints of their own national animal health systems are and if they know how different it can be from other national systems. 


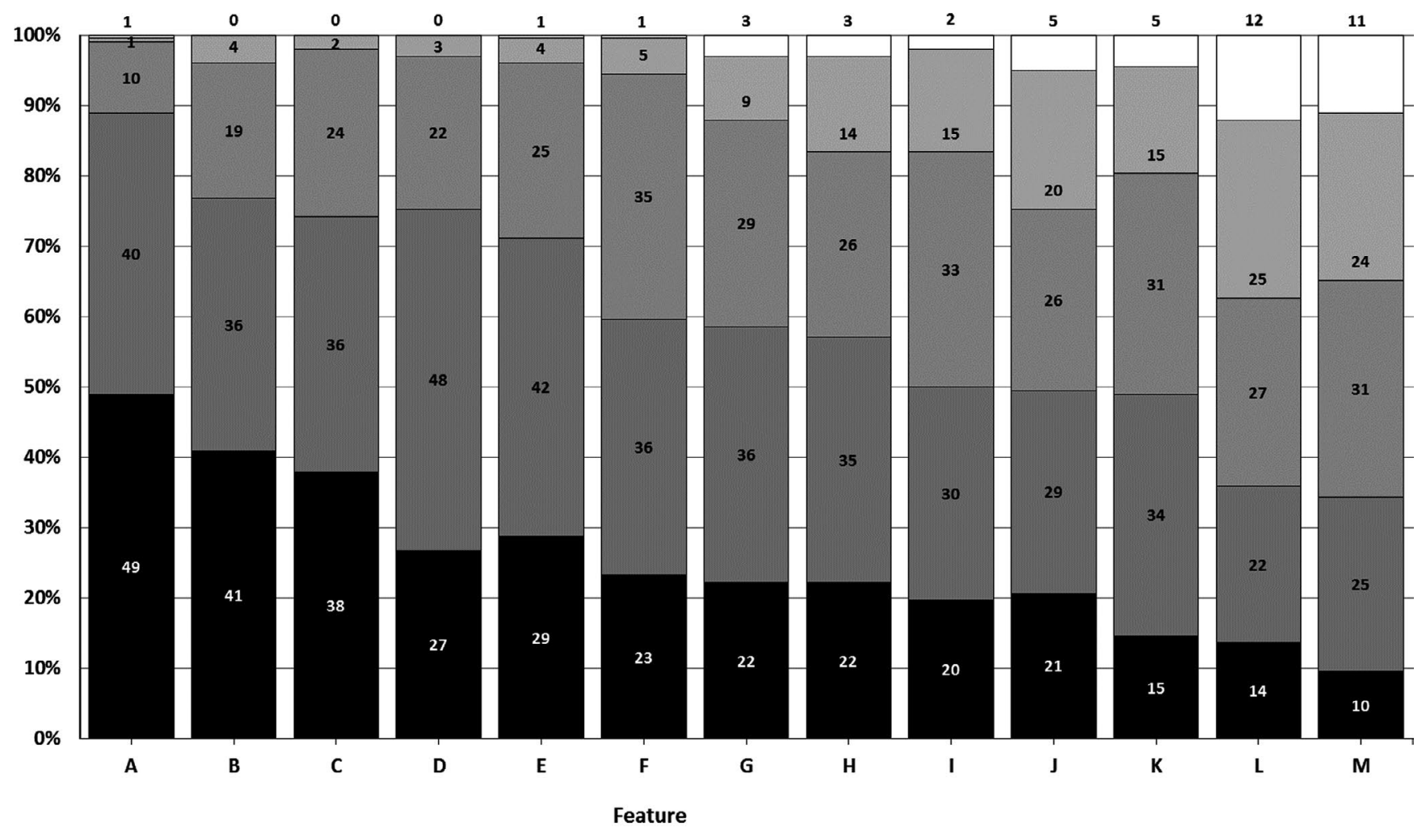

Extremely important $\quad \square$ Very important $\quad \square$ Important $\quad \square$ Slightly important $\quad \square$ Not important

FIGURE 10 Percentage of importance of the features they look for in an animal health system (N=198). (A) Data accessibility and availability; (B) Extraction of information; (C) Extraction of results/information; (D) Display of information; (E) User friendly; (F) The way the results are displayed; (G) Easy to find during web search; (H) Risk assessment methodologies; (I) Easy contact for help, queries and other information; (J) Access software and information while off campus/work space; (K) Publications regarding the tool used; (L) Login fewer times with fewer user accounts and passwords; (M) Be able to customize the interface and functionality that you use. Footnote: When asked if they had encountered issues with using different animal health platforms or risk analysis tools due to the fact these were not adaptable to their country's conditions, $45 \%$ said yes and $55 \%$ no

TAB LE 4 Average percentage of satisfaction and frequency of use by platform usage

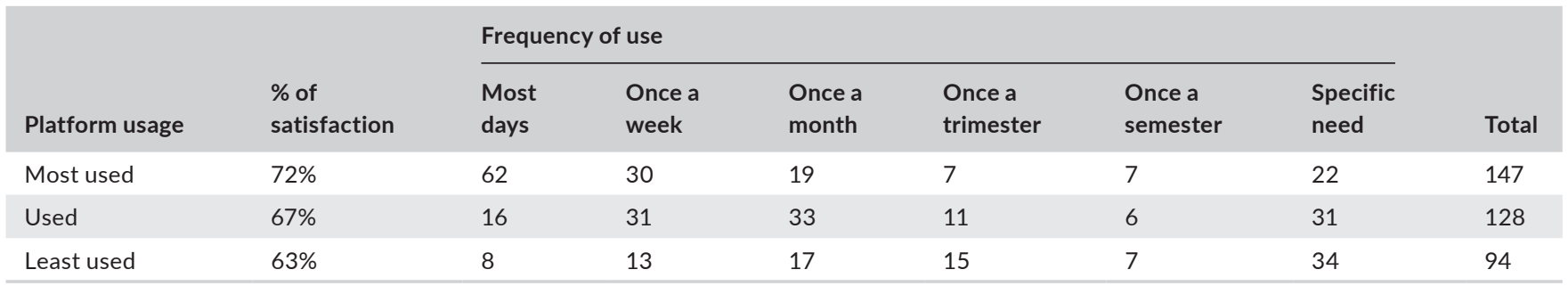

Likewise, they could be asked whether standardization of systems can help to improve the effectiveness of such systems. Even so, the survey showed that it is imperative that instruction manuals or online courses regarding different systems should be included in animal health systems and risk analysis tools. Additional training skills and collaborations though multidisciplinary discipline (e.g. mathematicians, laboratory specialists) with harmonization of animal health systems, in regard to data collection and accessibility should be encouraged, to provide useful and reliable data, both at the national and the international levels for both animal and human health.

Risk analysis tools are key for decision makers and policy developments when there is a disease incursion. Owing to the lack of relevant data and the very short period of time usually allowed to assess animal health risk on particular topics (Sharma \& Baldock, 1999; Vos et al., 2019), many institutions use a qualitative risk method for evaluating animal health risks or crises (Dufour et al., 2011). Results of this survey show an agreement with this point, where as previously mentioned many respondent's had problems in obtaining and acquiring data and thus, $70 \%$ of the respondents working in the risk analysis field who answered this survey use a qualitative risk assessment approach. Overall respondents use the risk analysis tools to produce risk assessments when epidemics have begun, as to be able to swiftly provide stakeholders and decision makers with the correct relevant information to stop the diseases from entering an 


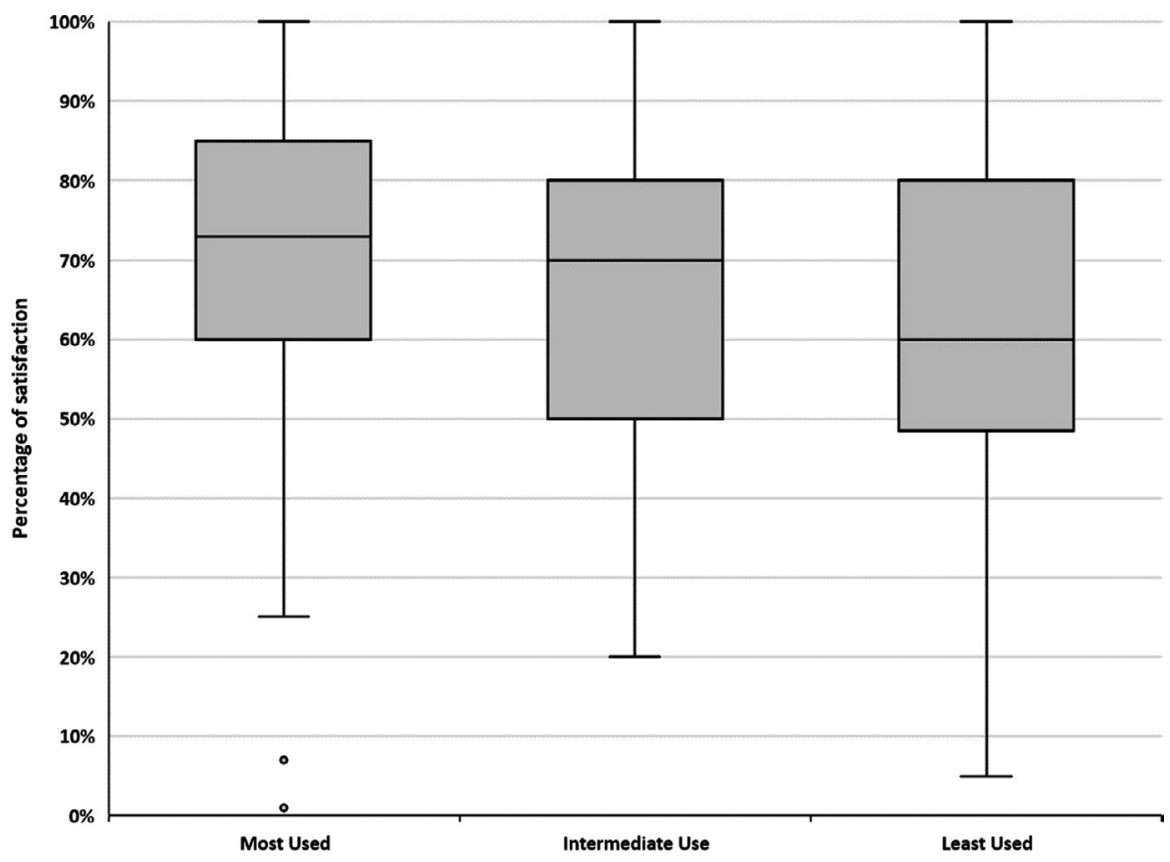

FIGURE 11 Boxplots of the percentage of satisfaction by degree of platform usage, most used, used and least used platform. Most used $(N=147)$; Intermediate use $(N=128)$; Least used $(N=94)$. The solid line across the boxes represents the median of the score distribution between the different experts; each rectangle below and above the solid line represent, respectively, the first and the third quartiles; ; adjacent lines to the whiskers represent the limits of the $95 \%$ confidence interval; small circles represent outside values uninfected area or reduce its spread. Thus, the features most sought in the risk analysis tools where spread assessment, and production of a quick risk assessment. The feature to being able to produce a report with it was also significant. It is therefore important for a risk analysis tool to have a feature which facilitates risk communication for stakeholders and decision makers in a quickly precise manner.

The three publicly available global animal health information systems (i.e. WAHIS, empres-i and Promed) were the most mentioned during the survey. This does not necessarily mean that national animal health information systems are less useful than international ones and should not be overlooked as these should be the first in gathering animal information. Moreover, nations contribute to those global animal health information systems as members. Sharma and Baldock, (1999) described them as: 'the complete system responsible for handling information about the health of livestock on a country'. The preference of these over national animal systems is most likely due that different countries have different animal information systems, and also access may be restricted by data protection issues or constrained by political or trade implications. There is also the fact that not all countries have an infrastructure where a good surveillance system is in place where data is collected and collated into a computerized system. Thus, expert may have to refer to global animal health information systems. The level of satisfaction was higher in platforms which where most used, but this is unsurprisingly as the platform's functionality per se attracts the user. It could be said however, that although the difference among the three medians of satisfaction was significant, the range was not large $75 \%$ - $64 \%$. This suggests that there should be a focus on increasing the platform functionalities in particular as previously mentioned, its data accessibility and ability to extract information in the desired format as these same issues mentioned earlier where those reported by the experts in the comments about the platforms.

The present survey showed that animal health systems and risk analysis tools are pivotal for professionals in the areas of veterinary and public health and the main issues and constraints includes access and extraction of relevant data. The systems and tools in place should also have a form of instructing as to help professionals make the best and most efficient analysis of diseases which may affect livestock and human population. In addition, animal health information systems should also be used to handle information about non-production domestic animals (such as pets) and wildlife. This question was not asked, but for future works, it would be interesting to know if there is such data and how accessible the information is.

\section{5 | CONCLUSION}

As diseases evolve and change through time, and countries are becoming more efficient at recording disease events, updating systems is the way to move forward. Surveys such as this one give insights of what can be done to improve current animal information systems. This survey provided a general overview of the needs, preferences and constraints that professionals have with current animal information systems or risk analysis tools. From these results, it is clear that for professionals who work in animal and public health, epidemiology and surveillance, animal health systems and risk analysis tools are used in their daily work. Not only to obtain data, but also to produce reports, and gather disease information. The overall majority is homogenous in what preferences they have regarding the type of information, and from many different parts of the world. It is essential that animal information systems not only to contain data on incidence and cases but also be more specific regarding risk pathways and spread assessment. The data or information should be i) easily accessible keeping in consideration privacy issues, and accessible to different regions of the world as well as ii) user friendly. Requirements for ease and flexibility of data extraction were highly rated. Standard data formats were preferred as this expedited the work required for risk estimation analyses or simple 
descriptive report production. This could ease and strengthen analysis done by different professionals, which would improve surveillance and as such impede future animal disease incursions.

\section{ACKNOWLEDGMENTS}

The authors would like to thank the colleagues who contributed to the development, reviewing (M. Dispas and V. De Waele), implementation and outreach of the survey, as well as all the colleagues around the world who dedicated part of their time to fill in the questionnaire. We would also like to thank the World Organisation for Animal Health (OIE), which agreed to support us in spreading out the survey through their mailing lists. This study was funded by the Belgian Federal Public Service Health, Food Chain Safety and Environment, through the MORISKIN research project RT18/2 implemented by Liège University, Hasselt University, Avia-GIS and Sciensano.

\section{CONFLICT OF INTEREST}

The authors declare no conflict of interest.

\section{ETHICAL APPROVAL}

Due to the nature of the study and the low risk exposure of the participants, formal approval from an Ethics Committee was not a requirement at the time of the study.

\section{DATA AVAILABILITY STATEMENT}

The data that support the findings of this study are available from the corresponding author upon reasonable request.

\section{ORCID}

Claude Saegerman iD https://orcid.org/0000-0001-9087-7436

\section{REFERENCES}

Beard, P. M. (2016). Lumpy skin disease: A direct threat to Europe. Veterinary Record, 178(22), 557-558. https://doi.org/10.1136/vr.i2800

Bellet, C., Humblet, M. F., Swanenburg, M., Vandeputte, S., Thebault, A., Gauchard, F., Hendrikx, P., Vos, C., Koeijer, A., Saegerman, C., \& Sanaa, M. (2012). External Scientific Final Report. Paris (France). Specification of data collection on animal diseases to increase the preparedness of the AHAW panel to answer future mandates CFP/EFSA/AHAW/2010/01. Report No.: EFSA-Q-2010-00903. Sponsored by the European Food Safety Authority. Retrieved from http://www.efsa.europa.eu/fr/supporting/pub/354e.htm

Bianchini, J., Humblet, M. F., Cargnel, M., Van Der Stede, Y., Koenen, F., De Clercq, K., \& Saegerman, C. (2020). Prioritization of livestock transboundary diseases in Belgium using a multicriteria decision analysis tool based on drivers of emergence. Transboundary Emerging Diseases, 67(1), 344-376. https://doi.org/10.1111/tbed.13356

Dufour, B., Plée, L., Moutou, F., Boisseleau, D., Chartier, C., Durand, B., Ganière, J. P., Guillotin, J., Lancelot, R., Saegerman, C., Thébault, A., Hattenberger, A. M., \& Toma, B. (2011). A qualitative risk assessment methodology for scientific expert panels. Revue Scientifique Et Technique, 10(1), 13-23.

FAO (2011). Challenges of animal health information systems and surveillance for animal disease and zoonoses. In: FAO Animal Production and Health (p. 1-124). Retrieved from http://www.fao.org/3/i2415e/i2415e00.htm

FAO (2014). Empres-i: Global Animal Disease Information System. Food and Agriculture Organisation of the United Nations, Rome. Retrieved from http://empres-i.fao.org/eipws3g/
Humblet, M.-F., Vandeputte, S., Albert, A., Gosset, C., Kirschvink, N., Haubruge, E., Fecher-Bourgeois, F., Pastoret, P.-P., \& Saegerman, C. (2012). Multidisciplinary and evidence-based method for prioritizing diseases of food-producing animals and zoonoses. Emerging Infectious Diseases, 18(4), https://doi.org/10.3201/eid1804.111151

Humblet, M.-F., Vandeputte, S., Mignot, C., Bellet, C., De Koeijer, A., Swanenburg, M., Afonso, A., Sanaa, M., \& Saegerman, C. (2016). How to Assess Data Availability, Accessibility and Format for Risk Analysis? Transboundary and Emerging Diseases, 63(2016), e173-e189. https:// doi.org/10.1111/tbed.12328

Linden, A., Licoppe, A., Volpe, R., Paternostre, J., Lesenfants, C., Cassart, D., Garigliany, M., Tignon, M., van den Berg, T., Desmecht, D., \& Cay, A. B. (2019). Summer 2018: African swine fever virus hits northwestern Europe. Transboundary and Emerging Diseases, 66(1), 54-55. https://doi.org/10.1111/tbed.13047

Lupo, C., Wilmart, O., Van Huffel, X., Dal Pozzo, F., \& Saegerman, C. (2016). Stakeholders' perceptions, attitudes and practices in the food chain. Food Control, 66, 158-165.

MINTRISK (2015). The Method for INTegrated RISK assessment for infectious diseases in animals allows the risk assessment of vector-borne diseases of livestock and pets. Developed by Wageningen BioVeterinary Research and Wageningen Economic Research. Retrieved from https://www.wecr.wur.nl/mintrisk/

Morris, R. S. (1991). Information systems for animal health: Objectives and components. Revue Scientifique Et Technique, 10(1), 13-23.

OIE (2017). WAHIS+, WAHIS is modernising: Be a partner in the project. Bulletin, 2, 24-26. https://doi.org/10.20506/bull.issue.2017.2.2635

OIE (2019). World Animal Health Information System. Retrieved from http://www.oie.int/wahis_2/public/wahid.php/Wahidhome/Home/

OIE (2020). Manual 6, Animal health information systems. (consulted at 28 June 2020). In Retrieved from https://rr-asia.oie.int/wp-content/ uploads/2019/09/seacfmd-manual-6.pdf

Sambri, V., Capobianchi, M., Charrel, R., Fyodorova, M., Gaibani, P., Gould, E., Niedrig, M., Papa, A., Pierro, A., Rossini, G., Varani, S., Vocale, C., \& Landini, M. P. (2013). West Nile virus in Europe: Emergence, epidemiology, diagnosis, treatment, and prevention. Clinical Microbiology \& Infection, 19(8), 699-704. https://doi.org/10.1111/1469-0691.12211

Sharma, P., \& Baldock, C. (1999). Understanding animal health in Southeast Asia: Advances in the Collection, Management and Use of Animal Health Information. Australian Centre for International Agricultural Research, Canberra, Australia, p. 3. Retrieved from http://aciar.gov. au/files/node/479/mn58-chapters1-6.pdf

SPARE (2010). Retrieved from https://spare-europe.shinyapps.io/ app_spare_v2/

Vos, C. J., Taylor, R. A., Simons, R. R. L., Roberts, H., Hultén, C., Koeijer, A. A., Lyytikäinen, T., Napp, S., Boklund, A., Petie, R., Sörén, K., Swanenburg, M., Comin, A., Seppä-Lassila, L., Cabral, M., \& Snary, E. L. (2019). Generic approaches for Risk Assessment of Infectious animal Disease introduction (G-RAID). EFSA Supporting Publications, 16(11), 87, https://doi.org/10.2903/sp.efsa.2019.EN-1743

\section{SUPPORTING INFORMATION}

Additional supporting information may be found online in the Supporting Information section.

How to cite this article: Bianchini J, Simons X, Faes C, et al. Assessing the use of animal health platforms: User's needs, preferences and constraints. Transbound Emerg Dis. 2021;00:1-15. https://doi.org/10.1111/tbed.14008 